Dublin Institute of Technology

ARROW@DIT

Articles

Crest: Centre for Research in Engineering Surface

Technology

2003-01-01

\title{
The Effect of Processing Conditions on Varistors Prepared From Nanocrystalline $\mathrm{ZnO}$
}

Suresh Pillai

Dublin Institute of Technology, suresh.pillai@dit.ie

Declan McCormack

John Kelly

Ramesh Raghavendra

Follow this and additional works at: http://arrow.dit.ie/cenresart

Part of the Nanoscience and Nanotechnology Commons

\section{Recommended Citation}

Pillai, S. C.* Kelly, J. M., McCormack, D. E., O’Brien, P. and Raghavendra, R. The effect of processing conditions on varistors prepared from nanocrystalline $\mathrm{ZnO}$ Journal of materials chemistry, 13, 2003, 2586-2590.

This Article is brought to you for free and open access by the Crest: Centre for Research in Engineering Surface Technology at ARROW@DIT. It has been accepted for inclusion in Articles by an authorized administrator of ARROW@DIT. For more information, please contact

yvonne.desmond@dit.ie, arrow.admin@dit.ie.

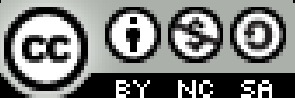




\title{
The effect of processing conditions on varistors prepared from nanocrystalline $\mathrm{ZnO}_{\dagger}^{\dagger}$
}

\author{
Suresh C. Pillai, ${ }^{a}$ John M. Kelly, ${ }^{* a}$ Declan E. McCormack, ${ }^{* b}$ Paul O’Brien ${ }^{c}$ and \\ Raghavendra Ramesh ${ }^{d}$ \\ ${ }^{a}$ Department of Chemistry, University of Dublin, Trinity College, Dublin 2, Republic of \\ Ireland. E-mail: jmkelly@tcd.ie; Fax: 353-1-6712826; Tel: 353-1-6081947 \\ ${ }^{b}$ School of Chemistry, Dublin Institute of Technology, Kevin Street, Dublin 8, Republic of \\ Ireland. E-mail: declan.mccormack@dit.ie; Fax: 353-1-4024989; Tel: 353-1-4024778 \\ ${ }^{c}$ The University of Manchester, Department of Chemistry and the Materials Science Centre, \\ Oxford Road, Manchester M13 9PL, UK \\ ${ }^{d}$ Littelfuse Ireland Ltd., Ecco Road, Dundalk, Republic of Ireland
}

\author{
Received 4th June 2003, Accepted 25th July 2003 \\ First published as an Advance Article on the web 12th August 2003
}

\begin{abstract}
Nanoparticles of $\mathrm{ZnO}$ were prepared by the reaction of ethanolic solutions of zinc acetate and oxalic acid followed by drying $\left(80^{\circ} \mathrm{C}\right)$ and calcination $\left(500^{\circ} \mathrm{C}\right)$. Subsequently varistor materials were fabricated from this nanoparticular ZnO via two separate routes:- a) from a "core shell" material using metal salts as additives; b) by using a conventional solid state mixing of metal oxides. Sintering $\left(1050{ }^{\circ} \mathrm{C}\right)$ and subsequent electrical studies were carried out for each of these samples and they were compared with commercial varistor samples prepared under similar conditions. "Core shell" type varistor material showed considerably higher breakdown voltage $\left(V_{\mathrm{c}}=850 \pm 30 \mathrm{~V} \mathrm{~mm}^{-1}\right)$ as compared to a sample prepared by mixing with metal oxides $\left(V_{\mathrm{c}}=683 \pm\right.$ $\left.30 \mathrm{~V} \mathrm{~mm}^{-1}\right)$ or commercial varistor discs $\left(V_{\mathrm{c}}=507 \pm 30 \mathrm{~V} \mathrm{~mm}^{-1}\right)$. The high breakdown voltage obtained is attributed to the formation of more varistor-active grain boundaries per unit area.
\end{abstract}

\section{Introduction}

Varistors are electronic ceramic devices whose function is to limit voltage surges by becoming strongly conducting at a breakdown voltage $\left(V_{\mathrm{c}}\right) .^{1-4}$ The method of preparation, crystalline size and additive homogeneity are the critical parameters to produce a better varistor material. ${ }^{5-12}$ Varistors with inhomogeneous microstructure can cause a large spread in current/voltage characteristics due to high local currents and this leads to the degradation of the varistor during electrical operation. $^{2,6,8,11}$ It is well documented that electrical and electronic characteristics can be altered by varying the microstructure at the grain boundaries,,$^{2,11-15}$ and careful control of the microstructure is required to produce a high performance varistor. Commercial varistors are usually fabricated by solid state mixing of 0.5 to $3 \mu \mathrm{m} \mathrm{ZnO}$ particles with dopant oxides such as $\mathrm{Bi}_{2} \mathrm{O}_{3}, \mathrm{Sb}_{2} \mathrm{O}_{3}, \mathrm{CoO}, \mathrm{MnO}, \mathrm{NiO}$ and $\mathrm{Cr}_{2} \mathrm{O}_{3},{ }^{2,5-7,11}$ the mixed powder then being pressed and sintered at higher temperatures. The final grain size after sintering is of the order of $8-12 \mu \mathrm{m}$ and the corresponding breakdown voltage $\left(V_{\mathrm{c}}\right)$ is around $200-300 \mathrm{~V} \mathrm{~mm}^{-1}$ for conventional varistors. This is equivalent to a voltage drop of 1.5-3.0 V per inter granular barrier, ${ }^{2,5,8}$ as the breakdown voltage of the sintered body is proportional to the number of grain boundaries.

With improved chemical and physical properties over their single counterparts, "core shell" materials are potentially useful in a broad range of applications. ${ }^{16-21}$ The shell may alter

$\dagger$ Electronic supplementary information (ESI) available: 1) EDX associated with HRTEM of the nano-ZnO sample before and after coating with $\mathrm{Sb}, \mathrm{Bi}$ and $\mathrm{Co}$; 2) HRTEM and EDX associated with HRTEM of the varistor powder calcined at $300{ }^{\circ} \mathrm{C}$ after the addition of all the dopants and 3) EDX associated with FESEM of the core shell varistor sample sintered at $1050{ }^{\circ} \mathrm{C}$. See http://www.rsc.org/suppdata/ $\mathrm{jm} / \mathrm{b} 3 / \mathrm{b} 306280 \mathrm{e} /$ the charge, functionality and dispersibility of the colloidal core and encasing colloids in a shell of different composition may also protect the core from extraneous chemical and physical changes. By homogeneously coating each spherical particle, more varistor-active grain boundaries per unit area will be formed by dopants compared to the conventional techniques. ${ }^{5}$ Grain growth is also expected to be much less, as each grain should be homogeneously covered with dopants (grain growth inhibitors). This may also lead to a decrease in the sintering temperature required.

In this paper we report a new procedure for the formation of nanoparticular $\mathrm{ZnO}$ and the preparation of varistors from it a) using materials in which the dopant oxides were deposited on the nanoparticular core; b) by simply mixing with solid metal oxides. It was hoped that these procedures would lead to varistors with higher breakdown voltage due to the large number of grain boundaries. Such materials are required for applications for device miniaturisation.

\section{Experimental}

\section{Reagents}

Zinc acetate dihydrate (Riedel-de Haen, 99.5\%), bismuth(III) chloride (Aldrich, 98\%), antimony(III) chloride (Aldrich, 99\%), cobalt(III) chloride hexahydrate (Aldrich, 98\%), manganese(II) acetate tetrahydrate (Aldrich, 99\%), nickel(II) acetate tetrahydrate (Aldrich, 99\%), chromium(III) nitrate nonahydrate (Aldrich, 99\%) and aluminium nitrate nonahydrate (Aldrich, $99 \%)$ were used as received.

$\mathrm{ZnO}$ (Grillo), $\mathrm{Bi}_{2} \mathrm{O}_{3}$ (Ferro corporation), $\mathrm{Sb}_{2} \mathrm{O}_{3}$ (Cookson), $\mathrm{CoO}$ (Outokumpu), $\mathrm{MnO}$ (Campbell Chemicals), $\mathrm{NiO}$ (Campbell Chemicals), $\mathrm{Cr}_{2} \mathrm{O}_{3}$ (Merck), $\mathrm{Al}_{2} \mathrm{O}_{3}$ (Merck) (all reagent grade) and commercial varistor powder were supplied by Littelfuse Ltd, Dundalk. 


\section{Synthesis of nanoparticular $\mathrm{ZnO}$ (nano-ZnO)}

In a typical experiment, zinc acetate dihydrate (10.98 g, $50 \mathrm{mmol})$ was treated with ethanol $(300 \mathrm{ml})$ in a rotary evaporator at $60{ }^{\circ} \mathrm{C}$ under slightly reduced pressure. The salt was completely dissolved in 20-40 minutes. Oxalic acid dihydrate $(12.6 \mathrm{~g}, 100 \mathrm{mmol})$ in ethanol $(200 \mathrm{ml})$ was simultaneously prepared by stirring for 10 minutes at $50{ }^{\circ} \mathrm{C}$. The oxalic acid solution was slowly added with stirring to the warm ethanolic solution containing $\mathrm{Zn}^{2+}$. The thick white gel obtained was dried in an oven set at $80{ }^{\circ} \mathrm{C}$ for 20 hours. This xerogel was calcined by heating to $500{ }^{\circ} \mathrm{C}$ and held at this temperature for 2 hours using a ramp rate of $3{ }^{\circ} \mathrm{C} / \mathrm{min}$ in a chamber furnace to yield nanoparticular $\mathrm{ZnO}$ (nano- $\mathrm{ZnO}$ ).

\section{Coating of dopants on nano-ZnO}

Nano-ZnO (2 g, $24.5 \mathrm{mmol})$ prepared as above was dispersed in ethanol $(200 \mathrm{ml})$ in a conical flask and ultrasonicated for 40 minutes. Antimony chloride $(0.1471 \mathrm{~g}, 0.64 \mathrm{mmol})$ and cobalt chloride hexahydrate $(0.066 \mathrm{~g}, 0.27 \mathrm{mmol})$ were dissolved in ethanol $(20 \mathrm{ml})$ in a beaker. Bismuth chloride $(0.081 \mathrm{~g}$, $0.25 \mathrm{mmol})$ was dissolved in acetone $(10 \mathrm{ml})$. Solutions of the above antimony, cobalt and bismuth chlorides were added to the ethanolic suspension of zinc oxide and stirred for 5 minutes. Ammonium carbonate $(4 \mathrm{ml}, 0.1 \mathrm{M})$ was added to the above solution and stirred for 10 minutes. (A sample was taken, dried at $80{ }^{\circ} \mathrm{C}$ and subsequently examined by HRTEM). An ethanolic solution $(20 \mathrm{ml})$ of nickel acetate tetrahydrate $(0.042 \mathrm{~g}, 0.17 \mathrm{mmol})$, manganese acetate tetrahydrate $(0.062 \mathrm{~g}, 0.25 \mathrm{mmol})$, chromium nitrate nonahydrate $(0.1032 \mathrm{~g}$, $0.25 \mathrm{mmol})$ and aluminium nitrate nonahydrate $(0.0017 \mathrm{~g}$, $0.0046 \mathrm{mmol}$ ) was added to the above mixture and stirred for 20 minutes. The material thus obtained was dried in an oven at $80{ }^{\circ} \mathrm{C}$ and further calcined at $300{ }^{\circ} \mathrm{C}$. This mixture was then plastified with 1 drop each of $10 \%$ aqueous solution of poly(vinyl alcohol) and poly(ethylene glycol) and $0.015 \mathrm{~g}$ of gum arabic. This was further dried in an oven $\left(100{ }^{\circ} \mathrm{C}\right)$ for 5 minutes and pelletised into $7 \mathrm{~mm}$ (diameter) $\times 0.7 \mathrm{~mm}$ (thickness) discs before sintering at $1050{ }^{\circ} \mathrm{C}$ for 2 hours in a furnace. The average thickness of the sintered pellets was $0.65 \mathrm{~mm}$.

\section{Addition of dopants to nano- $\mathrm{ZnO}$ using conventional solid state mixing}

Nano-ZnO was mixed with commercial oxide additives by conventional solid state mixing technique. In a typical experiment nano- $\mathrm{ZnO}(2 \mathrm{~g}, 24.5 \mathrm{mmol})$ calcined at $500^{\circ} \mathrm{C}$ was added to $\mathrm{Bi}_{2} \mathrm{O}_{3}(0.06 \mathrm{~g}, 0.13 \mathrm{mmol}), \mathrm{Sb}_{2} \mathrm{O}_{3}(0.094 \mathrm{~g}, 0.32 \mathrm{mmol}), \mathrm{MnO}$ $(0.022 \mathrm{~g}, 0.25 \mathrm{mmol}), \mathrm{NiO}(0.012 \mathrm{~g}, 0.16 \mathrm{mmol}), \mathrm{CoO}(0.021 \mathrm{~g}$, $0.28 \mathrm{mmol}), \mathrm{Cr}_{2} \mathrm{O}_{3}(0.0196 \mathrm{~g}, 0.13 \mathrm{mmol})$ and $\mathrm{Al}_{2} \mathrm{O}_{3}(0.00048 \mathrm{~g}$, $0.0047 \mathrm{mmol}$ ) and mixed in an agate mortar for 5 minutes. This mixture was then plastified, dried, pelletised and sintered as above.

\section{Instrumentation}

Infrared spectra of samples dispersed in $\mathrm{KBr}$ were recorded on a Genesis II FTIR Spectrometer. Measurements were carried out in the wavenumber range $400-4000 \mathrm{~cm}^{-1}$.

Differential Scanning Calorimetric (DSC) measurements were performed with a Rheometric Scientific DSC QC. A small amount of sample (less than $3 \mathrm{mg}$ ) was heated from room temperature to $500{ }^{\circ} \mathrm{C}$ at a constant heating rate of $10{ }^{\circ} \mathrm{C} /$ minute under nitrogen atmosphere. Thermo-Gravimetric Analysis (TGA) was carried out using a Thorn Scientific TG-750 instrument operated at a constant heat flow of $1{ }^{\circ} \mathrm{C} / \mathrm{min}$.

Samples for powder X-ray Diffraction (XRD) were prepared by making a thin film of the powder with acetone on a glass plate and the measurement was performed with a Siemens D
500 or Philips PW 1540 X-ray diffractometer. The particle sizes were calculated by using the Scherrer equation. ${ }^{13}$

$$
\text { Crystalline size }=\frac{0.9 \lambda}{\mathrm{B} \cos \theta}
$$

where $\lambda=\mathrm{X}$-ray wavelength, $\theta=$ Bragg angle $B=$ line broadening. The line broadening $\mathrm{B}$ is measured from the increased peak width at half the peak height and is obtained from Warren formula $B^{2}=B_{\mathrm{M}}{ }^{2}-B_{\mathrm{S}}{ }^{2}$ where $B_{\mathrm{M}}$ is the measured peak width and $B_{\mathrm{S}}$ is the corresponding width of a peak of a standard material (commercial $\mathrm{ZnO}$ ) whose particle size is greater than $200 \mathrm{~nm}$.

Transmission electron microscopy (TEM) was performed with a Hitachi 7000 TEM or Philips CM 20 HRTEM (High Resolution Transmission Electron Microscope). 400 mesh copper grids coated with Formvar were used to prepare the samples. Scanning Electron Microscopic (SEM) studies were carried out by FESEM (Hitachi S-4300), which was operated at $5.0 \mathrm{kV}$ or $20 \mathrm{kV}$. Samples for analysis were mounted on aluminium stubs and coated with graphite.

The BET surface area analysis was carried out using a Micromeritics Gemini 2370 instrument operating at liquid nitrogen temperature after degassing the samples for 2 hours at $200{ }^{\circ} \mathrm{C}$.

Density measurements of the pre-sintered and sintered samples were performed in water using an Ohaus densitometer 470007-010.

$\mathrm{I}-\mathrm{V}$ characteristics from $0.1 \mu \mathrm{A}$ to $10 \mathrm{~mA}$ were measured by using a Keithley Instrument (Model 2410). The breakdown voltage $\left(V_{\mathrm{c}}\right)$ was measured as the voltage at a current density of $1 \mathrm{~mA}$. The nonlinear constant $\alpha$ was calculated by measuring the voltage $V_{2}$ and $V_{1}$ at current densities $I_{2}$ and $I_{1}(10 \mathrm{~mA}$ and $1 \mathrm{~mA}$ ) respectively and using the relationship:

$$
\alpha=\frac{\log \mathrm{I}_{2}-\log \mathrm{I}_{1}}{\log \mathrm{V}_{2}-\log \mathrm{V}_{1}}
$$

\section{Results and discussion}

\section{Synthesis of nano-ZnO}

Reaction of an ethanolic solution of zinc acetate with an ethanolic solution of oxalic acid produced a thick semi-gel. Subsequent drying at $80^{\circ} \mathrm{C}$ and calcination of this gel at $500{ }^{\circ} \mathrm{C}$ produced $\mathrm{ZnO}$ as identified by its powder X-ray diffraction pattern (Fig. 1).

The powder X-ray diffraction pattern shows $2 \theta$ values and relative intensities (except for the 002 plane) of the peaks coincident with JCPDS data of zincite. Broadening of the X-ray bands allowed an estimate of the average particle size as $27 \pm 5 \mathrm{~nm}$ using the Scherrer equation. ${ }^{13}$ This was confirmed using transmission electron microscopy (Fig. 2) which revealed that the material consisted of agglomerates of spherical particles with a diameter of $34 \pm 5 \mathrm{~nm}$. The BET surface area for material calcined at $500{ }^{\circ} \mathrm{C}$ was found to be $17 \mathrm{~m}^{2} \mathrm{~g}^{-1}$.

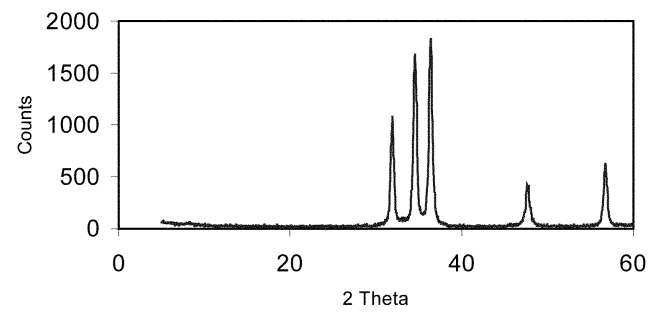

Fig. 1 X-ray powder diffraction plot of $\mathrm{ZnO}$ material calcined at $500{ }^{\circ} \mathrm{C}$. 

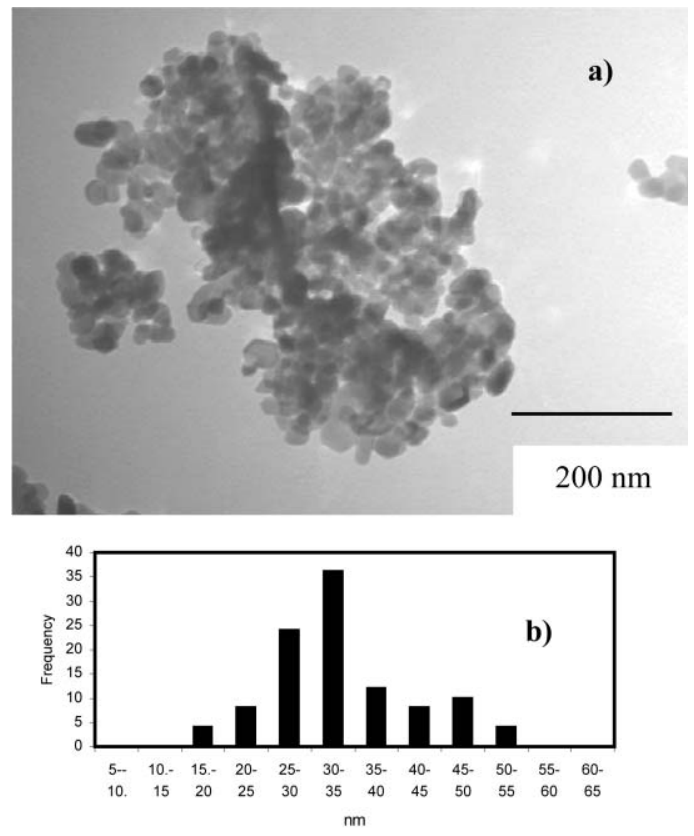

Fig. 2 a) TEM image of $\mathrm{ZnO}$ powder calcined at $500{ }^{\circ} \mathrm{C}$. b) Size histogram (TEM) of the nano-ZnO.

\section{FTIR analysis of the dried and calcined powder}

The FTIR spectrum of the xerogel $\left(80^{\circ} \mathrm{C}\right)$ retains some typical features of an acetate salt. ${ }^{14}$ Two principal peaks are observed at $1627 \mathrm{~cm}^{-1}$ and $1364 \mathrm{~cm}^{-1}$ corresponding to the asymmetric and symmetric stretching of the carboxyl group respectively. ${ }^{14}$ The bands at $3398 \mathrm{~cm}^{-1}$ and $2900 \mathrm{~cm}^{-1}$ are due to $\mathrm{OH}$ stretching and $\mathrm{CH}$ (acetate) stretching respectively (Table 1).

After heating to $250{ }^{\circ} \mathrm{C}$ the sample shows evidence for the presence of carboxylate groups but the characteristic peaks for the $\mathrm{CH}_{3}$ of acetate $\left(2900 \mathrm{~cm}^{-1}\right)$ are absent, suggesting the loss of acetic acid. Furthermore most of the water has been lost as evidenced by the weakening of the peak around $3400 \mathrm{~cm}^{-1}$. The $500{ }^{\circ} \mathrm{C}$ calcined sample is dominated by a very strong band at $450 \mathrm{~cm}^{-1}$ due to the $\mathrm{Zn}-\mathrm{O}$ stretching. The small signal at $3411 \mathrm{~cm}^{-1}$ observed is probably due to the contact of the $\mathrm{ZnO}$ sample with air resulting in adsorption of a small amount of water vapour. ${ }^{15}$

\section{Thermal analysis of the xerogel}

The thermogravimetric analysis of the xerogel $\left(80{ }^{\circ} \mathrm{C}\right)$ shows two stages of mass loss (Fig. 3). The first stage $\left(80-176{ }^{\circ} \mathrm{C}\right.$ ) involves a loss of $17 \%$ of the original mass and may be attributed to the removal of water and acetic acid. In the next stage, $48.5 \%$ of the material present at $176{ }^{\circ} \mathrm{C}$ is lost by $435{ }^{\circ} \mathrm{C}$. The residual mass $(51.5 \%)$ is close to the theoretical percentage of $\mathrm{ZnO}(53.0 \%)$ found from decomposition of anhydrous zinc oxalate.

DSC showed two well-defined endotherms with peaks at 160 and $440{ }^{\circ} \mathrm{C}$ (Fig. 4). These results are fully in agreement with the IR and TGA measurements showing the loss of acetic acid/ water below $200{ }^{\circ} \mathrm{C}$ and with the subsequent conversion of zinc

Table 1 FTIR analysis of the $\mathrm{ZnO}$ precursor gel dried at $80{ }^{\circ} \mathrm{C}$ (xerogel) and the xerogel calcined at 250 and $500{ }^{\circ} \mathrm{C}$

\begin{tabular}{llll}
\hline Assignment & $80{ }^{\circ} \mathrm{C}$ & $250{ }^{\circ} \mathrm{C}$ & $500{ }^{\circ} \mathrm{C}$ \\
\hline$v_{\text {asCOO}-}$ & $1627 \mathrm{vs}$ & $1621 \mathrm{~s}$ & \\
$v_{\mathrm{aCOO}-}$ & $1364 \mathrm{~s}$ & $1364 \mathrm{~s}$ & \\
$\delta_{\mathrm{COO}-}$ & $740 \mathrm{~s}$ & $750 \mathrm{w}$ & \\
$v_{\mathrm{OH}}$ & $3398 \mathrm{~s}$ & $3402 \mathrm{w}$ & $3411 \mathrm{vw}$ \\
$v_{\mathrm{CH}}\left(\mathrm{CH}_{3}\right)$ & $2900 \mathrm{vw}$ & & $450 \mathrm{vs}$ \\
$v_{\mathrm{Zn}-\mathrm{O}}(\mathrm{ZnO})$ & & & \\
\hline
\end{tabular}

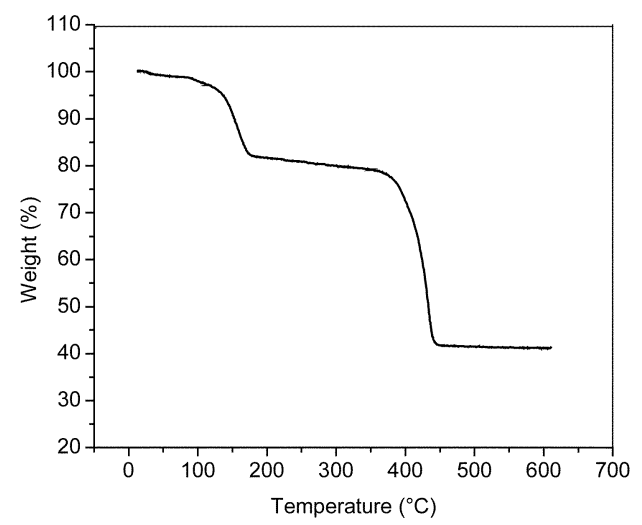

Fig. 3 TGA plot of the xerogel $\left(80^{\circ} \mathrm{C}\right)$.

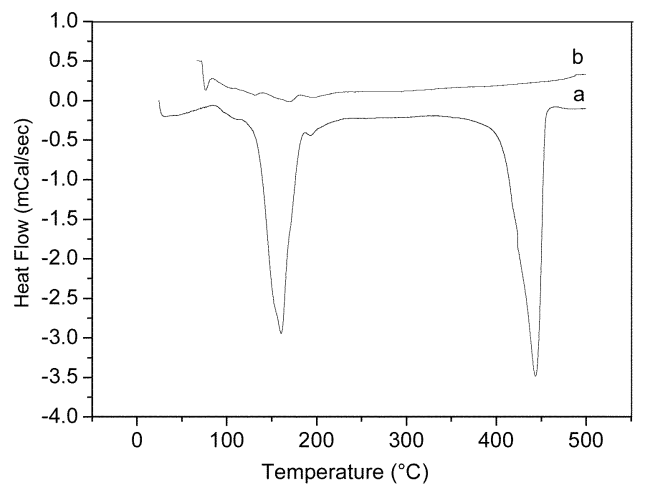

Fig. 4 DSC plot of the xerogel $\left(80^{\circ} \mathrm{C}\right)$ a) First scan b) Second scan.

oxalate to $\mathrm{ZnO}$ at $440{ }^{\circ} \mathrm{C}$. It is possible that the reaction is similar to that reported by Shen et $a l,{ }^{22}$ where $\mathrm{ZnO}$ is formed by a solid state reaction of zinc acetate and oxalic acid and to that of Guo et $a l,{ }^{23}$ where $\mathrm{ZnO}$ is obtained from the decomposition of $\mathrm{ZnC}_{2} \mathrm{O}_{4} \cdot 2 \mathrm{H}_{2} \mathrm{O}$.

\section{Coating of dopants}

To achieve a homogeneous coating of ( $\mathrm{Sb}, \mathrm{Bi}$, and $\mathrm{Co}$ ) oxides around the $\mathrm{ZnO}$ particle, solutions of chloride salts of these elements were mixed with a dispersion of nano- $\mathrm{ZnO}$ (as prepared above) and reacted with ammonium carbonate. This material was examined by HRTEM, which showed that the zinc oxide particles were modified by the precipitation of the $\mathrm{Sb}, \mathrm{Bi}$ and $\mathrm{Co}$ (Fig. 5). A core of well-formed zinc oxide (with a diameter of $\sim 25 \mathrm{~nm}$ ) is covered by a poorly densified layer some 2 to $10 \mathrm{~nm}$ thick, presumably due to the carbonates of $\mathrm{Sb}$,

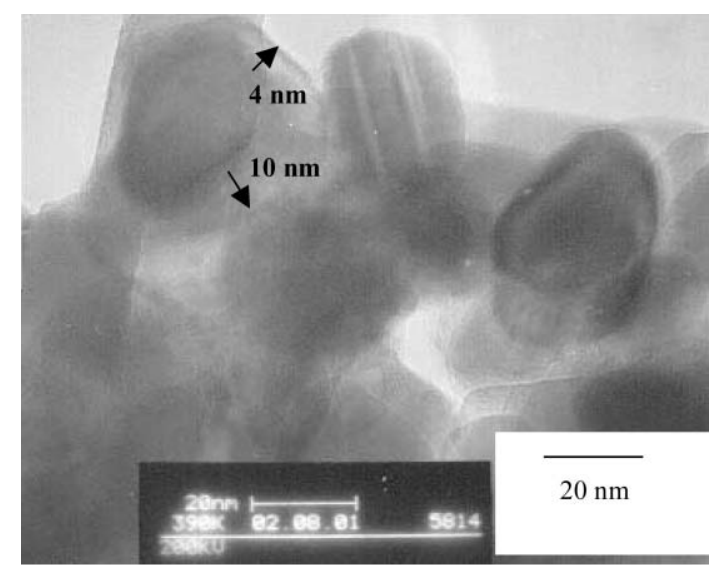

Fig. 5 HRTEM of $\mathrm{ZnO}$ nanoparticles coated with ( $\mathrm{Sb}, \mathrm{Bi}$ and $\mathrm{Co}$ ) oxide precursors. 
Table 2 Geometrical density values of the green (pre-sintered) samples

\begin{tabular}{lll}
\hline Varistor sample & $\begin{array}{l}\text { Geometrical } \\
\text { density/g cm }\end{array}$ & $\begin{array}{l}\text { Densification } \\
(\%)\end{array}$ \\
\hline "Core shell" (A) & 3.35 & 59.88 \\
Metal oxides (B) & 3.32 & 59.20 \\
Commercial (C) & 3.78 & 60.00 \\
\hline
\end{tabular}

$\mathrm{Bi}$ and $\mathrm{Co}$. The presence of $\mathrm{Sb}, \mathrm{Bi}$ and $\mathrm{Co}$ were further confirmed by EDX analysis (ESI Fig. S1). The above mixture was then mixed with an ethanol solution of nickel acetate, manganese acetate, chromium nitrate, and aluminium nitrate dried at $80{ }^{\circ} \mathrm{C}$ and subsequently calcined at $300{ }^{\circ} \mathrm{C}$ for 2 hours to remove any organic residue. This material was used to make varistor discs. EDX associated with HRTEM (ESI Fig. S2) of this material showed the presence of $\mathrm{Ni}, \mathrm{Cr}, \mathrm{Mn}, \mathrm{Co}$ and $\mathrm{Al}$. HRTEM (ESI Fig. S2 a and b) studies indicate that the size of these particles were in the range of 20 to $50 \mathrm{~nm}$. Core shell structure was not obvious in this case. This is probably due to the formation of dopant metal oxides from carbonates over the $\mathrm{ZnO}$ core while calcining at $300{ }^{\circ} \mathrm{C}$.

\section{Varistor properties of the doped $\mathrm{ZnO}$ materials}

Densification studies. Two routes to varistor material were followed: A) from the mixture prepared from "core shell" material and B) by solid state mixing of nano- $\mathrm{ZnO}$ with metal oxide dopants. Table 2 provides the average geometrical density values of these green (pre-sintered) pellets. It may be observed that both (A) and (B) were found to be consistent with the commercial varistor samples (where the $\mathrm{ZnO}$ is $c a$. $0.5 \mu \mathrm{m}$ in diameter).

These pellets were then sintered at $1050{ }^{\circ} \mathrm{C}$ and their density and electrical properties subsequently measured. These were then compared to those of a commercial varistor material (Table 3). It is clear that the varistors prepared from the novel post-treated "core shell" samples have achieved a higher densification than the others at this relatively low processing temperature. The better sintering in the former case can be explained by the homogeneous addition of dopant ions among the grains. ${ }^{6}$

Microstructural and electrical studies. Most metal oxide varistors contain $\mathrm{ZnO}$ grains as the major component with several other metal oxides as additives. $\mathrm{ZnO}$ without any additives is a nonstoichiometric n-type semiconductor with linear I-V behaviour. Each of the additives control one or more of the properties such as electrical characteristics, grain growth and sintering temperature. ${ }^{1,2}$ During sintering different phases are formed and the microstructure of a $\mathrm{ZnO}$ varistor comprises conductive $\mathrm{ZnO}$ grains surrounded by electrically insulating grain boundaries. The breakdown voltage of a sintered body is proportional to the number of grain boundaries between the electrodes. ${ }^{1,24}$ This therefore determines that the breakdown voltage depends inversely on the $\mathrm{ZnO}$ grain size. As the nanocrystalline material contains large grain boundary volumes, more varistor-active grain boundaries per unit volume can be produced, potentially leading to smaller dimension devices.

EDX analysis along with FESEM of the sintered "core shell"

Table 3 Densification and electrical properties of samples sintered at $1050{ }^{\circ} \mathrm{C}$ for $2 \mathrm{~h}$

\begin{tabular}{lllll}
\hline Varistor sample & $\begin{array}{l}\text { Sintered } \\
\text { density/g cm }\end{array}$ & $\begin{array}{l}\text { Densification } \\
(\%)\end{array}$ & $\begin{array}{l}\text { Vc } \\
( \pm 30) / V\end{array}$ & $\begin{array}{l}\alpha \\
( \pm 3)\end{array}$ \\
\hline "Core shell" (A) & 5.45 & 97.21 & 850 & 33 \\
Metal oxides (B) & 5.17 & 92.28 & 683 & 30 \\
Commercial (C) & 5.40 & 96.44 & 507 & 48 \\
\hline
\end{tabular}
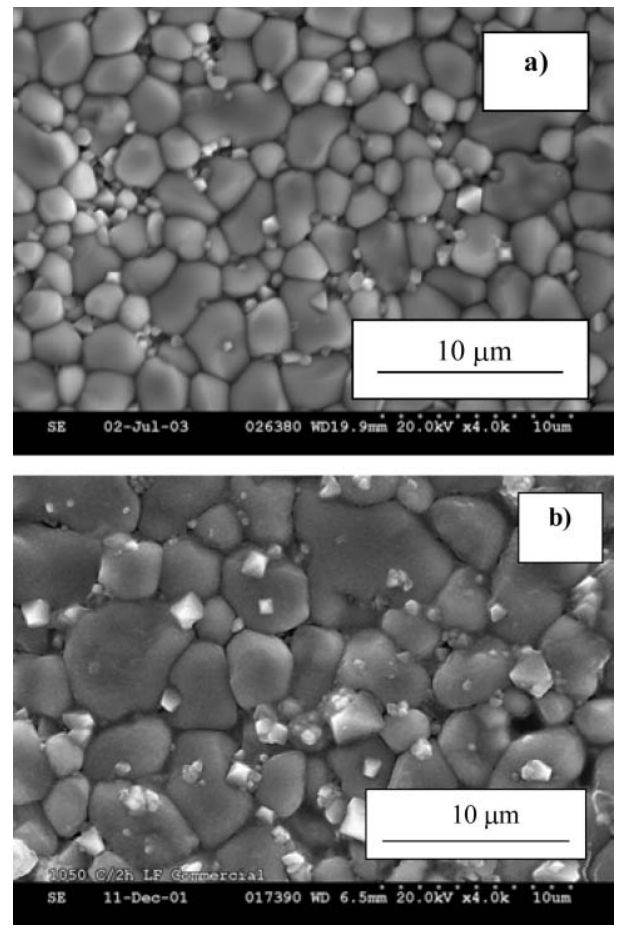

Fig. 6 FESEM images of the varistor samples sintered at $1050{ }^{\circ} \mathrm{C}$. a) "Core-shell" samples b) Commercial samples.

(ESI Fig. S3) and commercial samples show that dopants Sb, $\mathrm{Bi}, \mathrm{Co}, \mathrm{Cr}$, Ni and $\mathrm{Mn}$ are organised along the intergranular region. FESEM studies (Fig. 6) indicate a comparatively smaller average grain size $(1.5 \mu \mathrm{m})$ for "core shell" samples compared to the commercial samples $(3 \mu \mathrm{m})$.

The electrical properties of the sintered materials were studied. Breakdown voltages $\left(V_{\mathrm{c}}\right)$ and $\alpha$ values are given in Table 3. These results (Fig. 7) show a breakdown voltage $V_{\mathrm{c}}=$ $507 \pm 30 \mathrm{~V} \mathrm{~mm}^{-1}$ for commercial samples. Considerably higher $V_{\mathrm{c}}\left(683 \pm 30 \mathrm{~V} \mathrm{~mm}^{-1}\right)$ was obtained for varistors made from nano- $\mathrm{ZnO}$ mixed with metal oxides as additives, indicating that the smaller sized $\mathrm{ZnO}$ material somewhat improves the breakdown voltage. However, a much more striking effect was found with the varistors prepared from "core shell" materials, which showed much higher $V_{\mathrm{c}}(850 \pm$ $30 \mathrm{~V} \mathrm{~mm}^{-1}$ ) than that of the other two samples. This may be due to the fact that the "core shell" procedure produces a varistor powder with a greater homogeneity of the additives.

The above results point towards the formation of more grain boundaries by nano-structuring. This study has concentrated mainly on the grain size effect to achieve a high breakdown voltage, as this is the varistor property controlled by grain size. So far no effort has been made to optimise the $\alpha$ value, which could be facilitated by the variation of the dopant concentrations or alteration of the processing route.

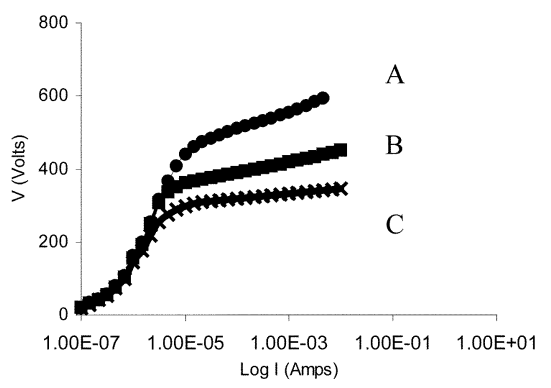

Fig. $7 \mathrm{I}-\mathrm{V}$ curve of varistor samples sintered at $1050{ }^{\circ} \mathrm{C} / 2 \mathrm{hr}$. $\mathrm{A}=$ varistors prepared from "core shell" samples. B = varistors prepared from nano- $\mathrm{ZnO}$ and metal oxides $\mathrm{C}=$ commercial varistor (the average thickness of the pellets was $0.65 \mathrm{~mm}$ ). 


\section{Conclusions}

A novel method for the preparation for nano- $\mathrm{ZnO}$ has been successfully performed and the material characterised by XRD and TEM. Thermal analysis and FTIR results are consistent with the formation of anhydrous zinc oxalate as an intermediate. "Core shell" type varistor powders were prepared by coating this nano- $\mathrm{ZnO}$ with additive metal salts. These materials showed a superior breakdown voltage, $\sim 70 \%$ higher than that of commercial varistors and also greater than the samples prepared simply by mixing nano- $\mathrm{ZnO}$ and metal oxides. These improvements are those expected from the smaller grain size and additive homogeneity produced by our "core shell" approach. With further modification, to improve the non-linearity and sintering, this novel route should be useful for the development of higher performance miniaturised devices.

\section{Acknowledgements}

The authors gratefully acknowledge the financial support of Enterprise Ireland (ARG/HE/1998/256), Littelfuse Ireland Ltd, PRTLI (Materials) and Enterprise Ireland/British Council (BC/2001/040). We thank the Centre for Microscopy and Analysis Trinity College Dublin and the Electron Microscopy Unit Manchester Materials Science Centre for their help with TEM and HRTEM respectively, Dr M. Venkatesan, Department of Physics, Trinity College Dublin, for thermogravimetric analysis and Mr Kevin Travers, Littelfuse Ireland, for help with sample preparation.

\section{References}

1 D. R. Clarke, J. Am. Ceram. Soc., 1999, 82, 485.

2 T. K. Gupta, J. Am. Ceram. Soc., 1990, 73, 1817.
3 M. Matsuoka, Jpn. J. Appl. Phys., 1971, 10, 736.

4 L. M. Levinson and H. R. Philip, Ceram. Bull., 1986, 65, 639.

5 R. N. Viswanath, S. Ramasamy, R. Ramamoorthy, P. Jayavel and T. Nagarajan, Nanostruct. Mater., 1995, 6, 993.

6 P. Duran, F. Capel, J. Tartaj and C. Moure, J. Am. Ceram. Soc., 2001, 84, 1661.

7 G. Westin, A. Ekstrand, N. Nygren, R. Osterlund and P. Merkelbach, J. Mater. Chem., 1994, 4, 615.

8 S. Hingorani, V. Pillai, P. Kumar, M. S. Multani and D. O. Shah, Mater. Res. Bull., 1993, 28, 1303.

9 C. W. Nahm, Solid State Commun., 2003, 126, 281.

10 S. Hishita, Y. Yao and S-I. Shirasaki, J. Am. Ceram. Soc., 1989, 72, 338 .

11 S. M. Haile, D. W. Johnson, Jr. G. H. Wiseman and H. K. Bowen, J. Am. Ceram. Soc., 1989, 72, 2004.

12 A. Sinha and B. P. Sharma, Mater. Res. Bull., 1997, 32, 1571.

13 A. R. West, Solid State Chemistry and Its Applications, John Wiley \& Sons, London, 1984, p. 174.

14 E. Reverchon, G. D. Porta, D. Sannino and P. Ciambelli, Powder Technol., 1999, 102, 127.

15 A. E. Jimenez-Gonzalez, J. A. S. Urueta and R. Suarez-Parra, J. Cryst. Growth, 1998, 192, 430.

16 Y. Fangli, H. Peng, Y. Chunlei, H. Shulan and L. Jinlin, J. Mater. Chem., 2003, 13, 634.

17 A. Glozman and E. Lifshitz, Mater. Sci. Eng., C., 2001, 15, 17.

18 G. Oldfield, T. Ung and P. Mulvaney, Adv. Mater., 2000, 12, 1519 .

19 A. Kay and M. Gratzel, Chem. Mater., 2002, 14, 2930.

20 M. A. Malik, P. O'Brien and N. Revaprasadu, Chem. Mater. 2002, 14, 2004.

21 C. Huber, M. Treguer-Delapierre, C. Elissalde, F. Weill and M. Maglione, J. Mater. Chem., 2003, 13, 650.

22 R. J. Shen, D. Z. Jia, Y. M. Qiao and J. Y. Wang, J. Inorg. Mater., 2001, 16, 625.

23 L. Guo, Y. Ji, H. Xu, Z. Wu and P. Simon, J. Mater. Chem., 2003, 13, 754 .

24 T. Asokan and R. Freer, J. Mater. Sci., 1990, 25, 2447. 